\title{
Influence of Structural and Textural States of Low-Carbon Steels on the Cracking Resistance of Tube Products
}

\author{
S. V. Danilov, a), N. V. Urtsev, 2, 3, b), K. B. Maslennikov',3, V. N. Urtsev², \\ and M. L. Lobanov ${ }^{1,4, c)}$ \\ ${ }^{1}$ B. N. Yeltsin Ural Federal University, 19 Mira St., Ekaterinburg, 620002, Russia \\ ${ }^{2}$ Ausferr Research and Technology Center, 18 Gorkogo St., Magnitogorsk, 455000, Russia \\ ${ }^{3}$ Nosov Magnitogorsk State Technical University, 38 Lenina Ave., Magnitogorsk, 455000, Russia \\ ${ }^{4}$ M. N. Miheev Institute of Metal Physics, Ural Branch of RAS, 18 S. Kovalevskoi St., Ekaterinburg, 620219, Russia \\ ${ }^{a}$ Corresponding author: s.v.danilov@bk.ru \\ b) urtsev@inbox.ru \\ c)m.1.lobanov@urfu.ru
}

\begin{abstract}
The texture of low-carbon low-alloy pipe steel sheet with bainitic structure produced by thermomechanical controlled processing (TMCP) is studied by means of electron backscatter diffraction (EBSD). The formation of cleavages during steel failure is related to the presence of ferrite grains with orientation $\{001\}<110>$ extended in the hot rolling direction. Two possibilities are shown for the formation of regions of easy crack propagation along the product obtained by TMCP.
\end{abstract}

\section{INTRODUCTION}

The thermomechanical controlled processing (TMCP) of low-carbon low-alloy pipe steel, which consists of controlled rolling with subsequent accelerated cooling, has reached a new level thanks to the introduction of specialized 5000 rolling mills at such Russian metallurgical plants as Severstal JSC, Magnitogorsk Iron and Steel Works (MMK) PJSC, and United Metallurgical Company (OMK) [1-3]. By means of TMCP, thick sheet (including sheet for pipelines) can be produced with distinctive combinations of strength, plasticity, cold strength, and weldability [4-6]. This is attributable to the great variability in the combinations of ferrite, bainite, and martensite structures obtained in the steel and to their morphological characteristics [1-7].

Research has shown that a feature of bainitic steels of strength classes X70 and X80 is the critical role of the formation (during tensile, impact bending, and static crack resistance tests) of secondary cracks within a fracture, i.e., separations propagating perpendicular to the main crack plane. It is important to note that separations are observed in contemporary large diameter pipes with ductile crack propagation $[8,9]$.

In the destruction of pipe steel sheets, an important role is played by a single weak component (001)[110] rather than by the integral texture, as shown in [10-13]. Crack development depends on the presence of extended regions with consistent orientation over a distance exceeding the critical crack size. In thermomechanical controlled processing, texture formation is mainly the result of two successive processes: hot deformation of austenite and shear phase transformation with controlled cooling.

In this paper, we investigate the mechanisms of the formation of structural and texture states (bainite, ferrite) in sheets of low-carbon low-alloy pipe steel obtained by TMCP, which allow crack propagation upon fracture.

Mechanics, Resource and Diagnostics of Materials and Structures (MRDMS-2020)

AIP Conf. Proc. 2315, 030006-1-030006-4; https://doi.org/10.1063/5.0037045

Published by AIP Publishing. 978-0-7354-4057-9/\$30.00 


\section{RESEARCH METHODS}

We investigate sheet samples of the $06 \mathrm{Mn} 2 \mathrm{MoNb}$ low-carbon low-alloy pipe steel containing $0.056 \mathrm{wt} \% \mathrm{C}$, $1.7 \mathrm{wt} \% \mathrm{Mn}, \sim 0.05 \mathrm{wt} \% \mathrm{Nb}$, and $\sim 0.05 \mathrm{wt} \% \mathrm{Mo}$. (The remainder is $\mathrm{Fe}$ and unavoidable impurities.) The steel consists primarily of bainite structure after thermomechanical controlled processing. It corresponds to strength class $\mathrm{X} 80$, with $\sigma_{0.2} \sim 575-585 \mathrm{~N} / \mathrm{mm}^{2}$ in the direction of deformation. At the end of isothermal hot rolling in TMCP, the temperature is close to the $\mathrm{Ac}_{3}$ value for the given steel $\left(\sim 830^{\circ} \mathrm{C}\right)$.

Electron microscopic study of the structure was carried out using a Tescan Mira3 scanning microscope with a field emission cathode at an accelerating voltage of $20 \mathrm{kV}$ (Fig. 1). An EBSD HKL Inca attachment with the Oxford Instruments analysis system was used to determine orientations of individual grains and to analyze local structure. The scanning interval was $0.1 \mu \mathrm{m}$. The error in lattice orientation determination was not more than plus or minus $1^{\circ}$ (plus or minus $0.6^{\circ}$, on average). The texture was investigated using direct pole figures (DPF).

The detection of coincidence site lattice (CSL) boundaries between grains was carried out by orientation mapping regarding the standard Brandon criterion plus or minus $\Delta \Theta$ preset in the software. It is of a certain value for each CSL boundary: $\Delta \Theta=15^{\circ} /(\Sigma \mathrm{n})^{1 / 2}$, where $\Sigma \mathrm{n}$ is the number of coincidence sites under overlapping of threedimensional crystal lattices.

\section{RESULTS AND DISCUSSION}

Under certain stress-strain conditions during controlled isothermal rolling with more than $90 \%$ reduction, a structure consisting of deformed austenite grains extended in the direction of rolling is formed over the whole sheet thickness. This structure is characterized by the same orientations that are stable for the FCC lattice: $\{112\}<111>$, $\{110\}<111>,<110\}<112>,\{110\}<001>[14]$.

The EBSD technique allowed us to define structural ferrite in the samples and to analyze the texture (Fig. 1). All the indicated orientations of ferrite formed in hot rolling, $\{001\}<110>,\{11 \mathrm{k}\}<110>$, are stable deformation orientations of the BCC lattice [14, 15]. It should be noted that, taking into account the crystal-geometric characteristics of structural ferrite (orientation, grain shape and size), it can be considered as a defect. Propagation of longitudinal cracks will be predetermined in the crystallographic planes $\{001\}$ of elongated ferrite grains [10-13]. Obviously, the elongated ferritic grains formed during hot rolling at temperatures below $\mathrm{Ac}_{3}$.

The analysis of the crystallographic relationship of the texture components and the structures obtained after TMCP shows that they can all be obtainedo in accordance with orientation relations intermediate between the Kurdjumov-Sachs and Nishiyama-Wasserman types, on the basis of the main textural orientations of rolled austenite $[10,16]$. The appearance of a limited number of orientations resulting from the $\gamma \rightarrow \alpha$ shear transformation in a material with initially complex multicomponent texture suggests the presence of structural factors that significantly limit the expression of all possible crystallite orientations in phase recrystallization [17-19].

In [20], using the $\mathrm{Cr} 18 \mathrm{Ni} 9$ steel as an example, it was shown that bainite crystallites take exactly recrystallization twin regions in the $\gamma$-phase. The first $\gamma \rightarrow \alpha$ transformation nuclei are generated not within one austenitic grain, but in neighboring grains, separated by the crystallographically determined CSL $\Sigma 3$ boundary, at the same time. As a result, elongated homogeneous regions of ferrite crystals will be formed connected by twin misorientation (or close to it). In this way the orientation relationship of the textural components of the initial material and the structure obtained by heat treatment can be explained in terms of the onset of phase transformations (both shear and diffusion transition) at crystallographically determined boundaries (including special boundaries) similar to the $\Sigma 3$ and $\Sigma 11$ CSL boundaries [18-20]. 


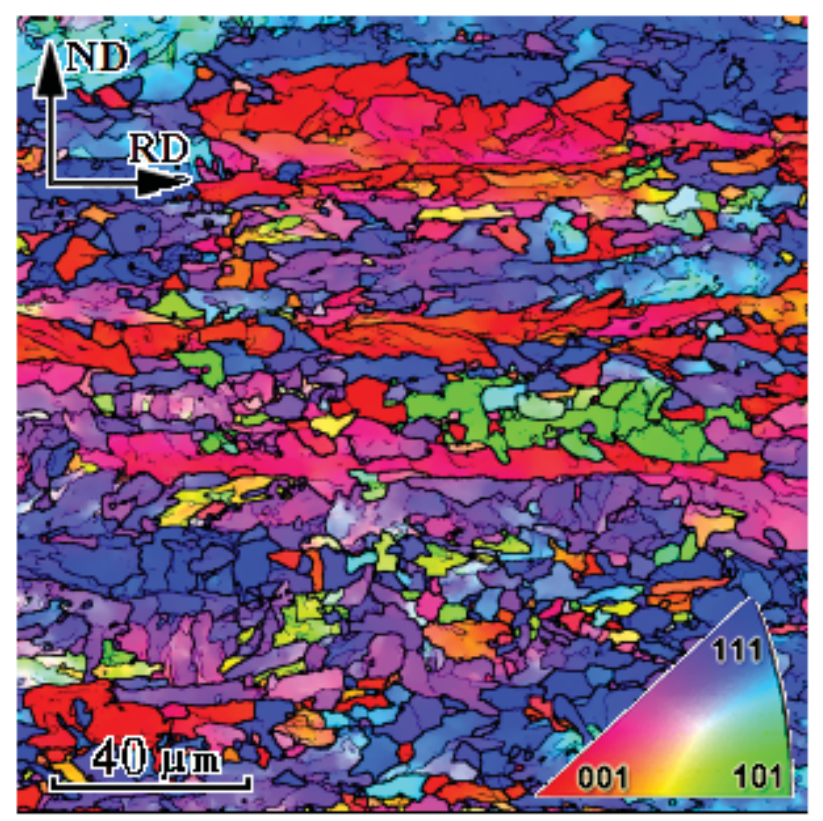

(a)

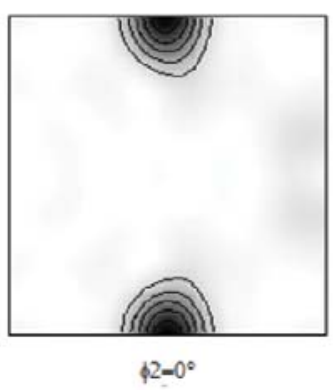

(c)

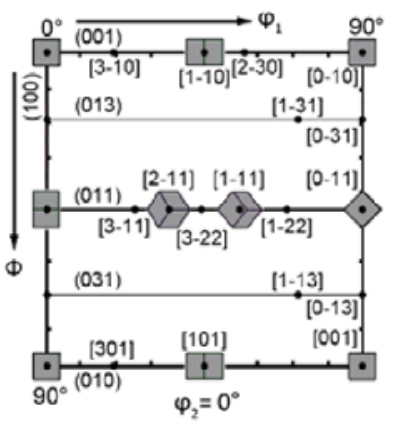

(d)

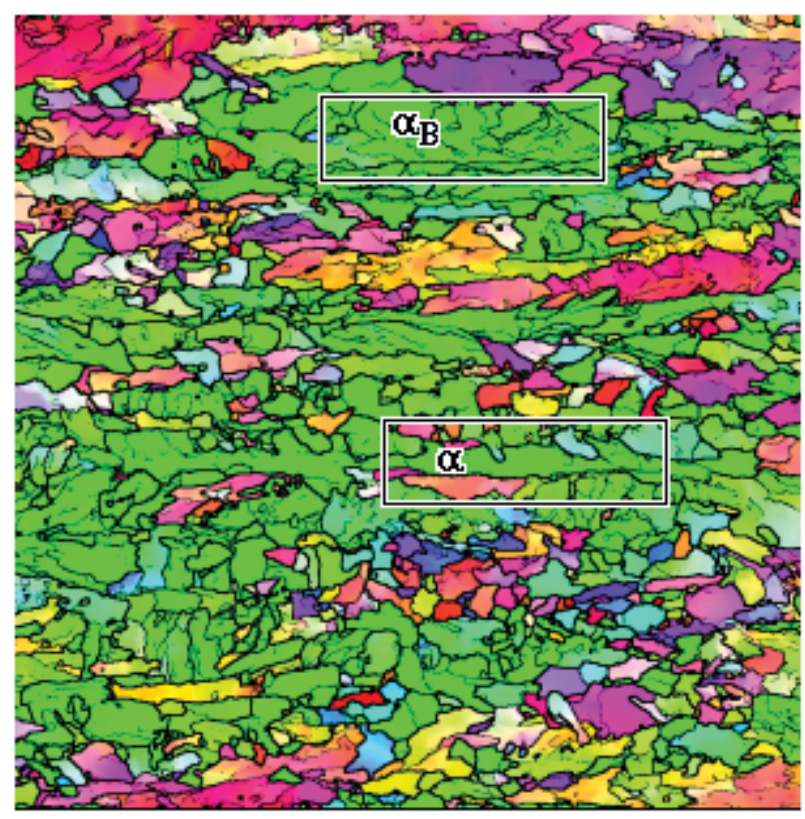

(b)

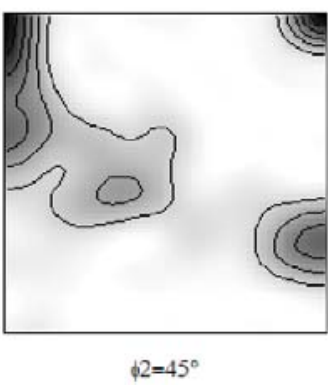

(e)

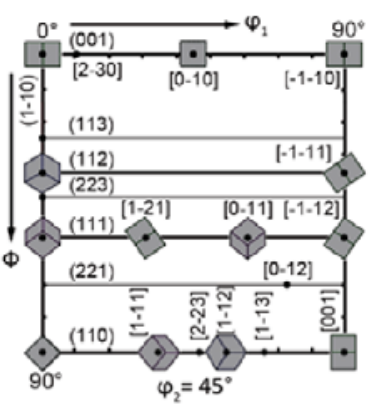

(f)

FIGURE 1. Microstructures in backscattered electrons $(\mathrm{a}, \mathrm{b})$ and texture as ODF sections $(\mathrm{c}, \mathrm{d})$ of the steel in TMCP; schematic orientations from the direction perpendicular to the RD-ND plane $(d, f) ; \alpha-$ ferrite, $\alpha_{B}-$ bainite

\section{CONCLUSION}

We have shown two possibilities for the formation of areas of easy crack propagation along the product obtained by TMCP.

1. There is the formation of ferritic grains during hot rolling at temperatures below the temperature of $\mathrm{Ac}_{3}$.

2. There is the formation of bainitic grains at special boundaries separating the deformed austenitic grains during steel cooling after hot rolling.

\section{ACKNOWLEDGMENTS}

The work was carried out using the equipment of the Laboratory of Structural Methods of Analysis and Properties of Materials and Nanomaterials of the Center of the Ural Federal University. The reported study was funded by the RFBR under research project No. 18-33-00135. We are grateful for the assistance rendered under the Program of Supporting the Leading Universities in the Russian Federation Aimed at Enhancing Their Competitiveness, government order No. 211, contract No. 02.A03.21.0006. 


\section{REFERENCES}

1. S. Yu. Nastich, Yu. D. Morozov, M. Yu. Matrosov, S. V. Denisov, V. V. Galkin, and P. A. Stekanov, Metallurgist 55(11-12), 810-818 (2012).

2. Yu. D. Morozov, E. A. Goli-Oglu, S. Yu. Nastich, S. V. Denisov, and P. A. Stekanov, Steel in Translation 42(2), 171-176 (2012).

3. V. I. Il'inskii, P. P. Stepanov, L. I. Efron, S. V. Golovin, V. V. Geier, M. Yu. Matrosov, E. A. Goli-Oglu, and O. P. Talanov, Metallurgist 58(1), 38-42 (2014).

4. E. Shigeru and N. Naoki, JFE Technical Report 20, 1-7 (2015).

5. M.-Sh. Zhao, K. Yang and Y. Shan, Materials Science and Engineering A 335, 14-20 (2002).

6. X. J. Liang, M. J. Hua, C. I. Garcia, and A. J. DeArdo, Materials Science Forum 762, 38-46 (2013).

7. M. L. Lobanov, M. L Krasnov, V. N. Urtsev, S. V. Danilov, and V. I. Pastukhov, Metal Science and Heat Treatment 61(1-2), 32-38 (2019).

8. G. Mannucci and G. Demofonti, The Journal of Pipeline Engineering 10(3), 133-145 (2011).

9. I. Y. Pyshmintsev, A. N. Mal'tseva, A. M. Gervas'ev, M. A. Smirnov, A. V. Korznikov, Steel in Translation 41(2), 157-164 (2011).

10. I. Yu. Pyshmintsev, A. O. Struin, A. M. Gervasyev, M. L. Lobanov, G. M. Rusakov, S. V. Danilov, and A. B. Arabey, Metallurgist 60(3-4), 405-412 (2016).

11. I. Yu. Pyshmintsev, A. M. Gervasyev, R. H. Petrov, V. C. Olalla, and L. Kestens, Materials Science Forum 702-703, 770-773 (2012).

12. M. A. Mohtadi-Bonab, M. Eskandari, and J. A. Szpunar, Materials Science and Engineering A 620, 97-106 (2014).

13. S. V. Danilov, E. R. Struina, and M. D. Borodina, Steel in Translation 47(3), 188-189 (2017).

14. M. Hölscher, D. Raabe, and K. Lücke, Acta Metallurgica et Materialia 42(3), 879-886 (1994).

15. G. M. Rusakov, M. L. Lobanov, A. A. Redikultsev, and I. V. Kagan, Steel in Translation 40(3), 219-224 (2010).

16. B. Hutchinson, L. Ryde, E. Lindh, and K. Tagashira, Materials Science and Engineering A 257(1), 9-17 (1998).

17. R. K. Ray and J. J. Jonas, International Materials Reviews 35, 1-36 (1990).

18. M. L. Lobanov, M. D. Borodina, S. V. Danilov, I. Yu. Pyshmintsev, and A. O. Struin, Steel in Translation 47(11), 710-716 (2017).

19. M. L. Lobanov, I. Y. Pyshmintsev, V. N. Urtsev, S. V. Danilov, N. V. Urtsev, and A. A. Redikultsev, Physics of Metals and Metallography 120(12), 1180-1186 (2019).

20. V. I. Pastukhov, A. V. Kozlov, and M. L. Lobanov, Solid State Phenomena 284, 253-258 (2018). 